Article

\title{
Techno-Economic Analysis of a 600 MW Oxy-Enrich Pulverized Coal-Fired Boiler
}

\author{
Ming Lei *, Cen Sun and Chunbo Wang \\ School of Energy and Power Engineering, North China Electric Power University, Baoding 071000, China; \\ suncener@163.com (C.S.); hdwchb@126.com (C.W.) \\ * Correspondence: ncepu_lm@126.com
}

Received: 6 March 2018; Accepted: 20 March 2018; Published: 28 March 2018

\begin{abstract}
Oxy-fuel combustion is one of the most promising methods for $\mathrm{CO}_{2}$ capture and storage (CCS) but the operating costs-mainly due to the need for oxygen production-usually lead to an obvious decrease in power generation efficiency. An "oxy-enrich combustion" process was proposed in this study to improve the efficiency of the oxy-fuel combustion process. The oxidizer for oxy-enrich combustion was composed of pure oxygen, air and recycled flue gas. Thus, the $\mathrm{CO}_{2}$ concentration in the flue gas decreased to $30-40 \%$. The PSA (pressure swing adsorption), which has been widely used for $\mathrm{CO}_{2}$ removal from the shifting gases of ammonia synthesis in China, was applied to capture $\mathrm{CO}_{2}$ during oxy-enrich combustion. The technological economics of oxy-enrich combustion with PSA was calculated and compared to that of oxy-fuel combustion. The results indicated that, compared with oxy-fuel combustion: (1) the oxy-enrich combustion has fewer capital and operating costs for the ASU (air separation unit) and the recycle fan; (2) there were fewer changes in the components of the flue gas in a furnace for oxy-enrich combustion between dry and wet flue gas circulation; and (3) as the volume ratio of air and oxygen was 2 or 3, the economics of oxy-enrich combustion with PSA were more advantageous.
\end{abstract}

Keywords: oxy-fuel combustion; oxy-enrich combustion; PSA; technological economy

\section{Introduction}

Traditional energy resources (coal, gas, oil, etc.) account for approximately half of all the electric power currently generated in the world [1-3]. Tremendous quantities of $\mathrm{CO}_{2}$ are produced from fossil fuel combustion every year. Among $\mathrm{CO}_{2}$-capturing technologies, oxy-fuel combustion is one of the most promising technologies [4-7]. However, compared with air combustion, extra energy is required (e.g., ASU (air separation unit) etc.) for oxy-fuel combustion, which can lead to a decrease in generating efficiency from 38.5\% (Supercritical pulverized coal plant) to 30.6\% (Supercritical oxy-fuel plant) [8]. This loss may be the largest obstacle for applications of oxy-fuel combustion, especially in developing countries.

A new approach that allows air to be partially used in oxy-fired coal power plants was proposed by Zanganeh [9] and Doukelis [10]. Techno-economic simulations and analysis of this type of technology were carried out by Zanganeh [9] and Huang [11]. The results showed that the novel oxy-fuel combustion system needed less auxiliary power from the ASU and circulating fan, based on capturing $\mathrm{CO}_{2}$ with full-scale cryogenic separation and its process efficiency was slightly lower than that of the full-scale oxy-fuel-based $\mathrm{CO}_{2}$ capture configuration. The most likely reason was that cryogenic separation was suitable for the capture of relatively high concentrations of $\mathrm{CO}_{2}$ (approximately 60\%) [12]. Techno-economic simulations of the modified oxy-fuel combustion system with MEA (monoethanolamine) [10] showed the total electricity generation cost of the novel system (per net electricity) was lower than that of pure oxy-fuel or post-combustion $\mathrm{CO}_{2}$ capture technologies. 
Based on the modified oxy-fuel technology, "oxy-enrich combustion" has been defined in our previous research [13]. By adjusting the volume of air mixed with oxygen entering the furnace, the $\mathrm{CO}_{2}$ volume concentration in the flue gas was limited to approximately $30-40 \%$. The range of $30-40 \%$ was chosen because PSA (pressure swing adsorption) was a highly efficient, low energy consumption technology for the separation and purification of $\mathrm{CO}_{2}$, which had become a competitive $\mathrm{CO}_{2}$ capturing technology [14]. Japan is a pioneer in using PSA for separating $\mathrm{CO}_{2}$, where PSA has mainly been applied to the power plant and manufacturing industries $[15,16]$. However, there are several difficulties when PSA technology is applied to a modern power plant due to a lower $\mathrm{CO}_{2}$ concentration (3-20\%) and an enormous flue gas volume [17]. PSA technology for $\mathrm{CO}_{2}$ removal from the shifting gases of ammonia synthesis has been commercialized in China, where the $\mathrm{CO}_{2}$ concentration is approximately $30-40 \%$. This technology has been verified successfully in modern industry. According to the "oxy-enrich combustion" mode suggested in this study, the $\mathrm{CO}_{2}$ concentration in flue gas is approximately $30-40 \%$ and the flue gas volume is less than half that of air combustion; therefore, it provides the possibility for the use of PSA technology in modern power plants, even in a $600 \mathrm{MW}$ or more coal-fired boiler.

Because "oxy-enrich combustion" is a novel technology recently proposed by scholars, there have been few discussions relating to the "oxy-enrich combustion." In this investigation, the "oxy-enrich combustion" mode is discussed in detail. In addition, using a $600 \mathrm{MW}$ pulverized coal boiler as an example, a techno-economic analysis for oxy-enrich combustion plus PSA was conducted to provide a reference for the practical application of this technology.

\section{Technical Description}

\subsection{Oxy-Fuel Combustion Technology}

The oxy-fuel combustion process-where air is replaced with oxygen supplied by the ASU—burns the fuel in a mixture of oxygen and recycled flue gas to produce an enriched $\mathrm{CO}_{2}$ flue gas [18], as shown in Figure 1.

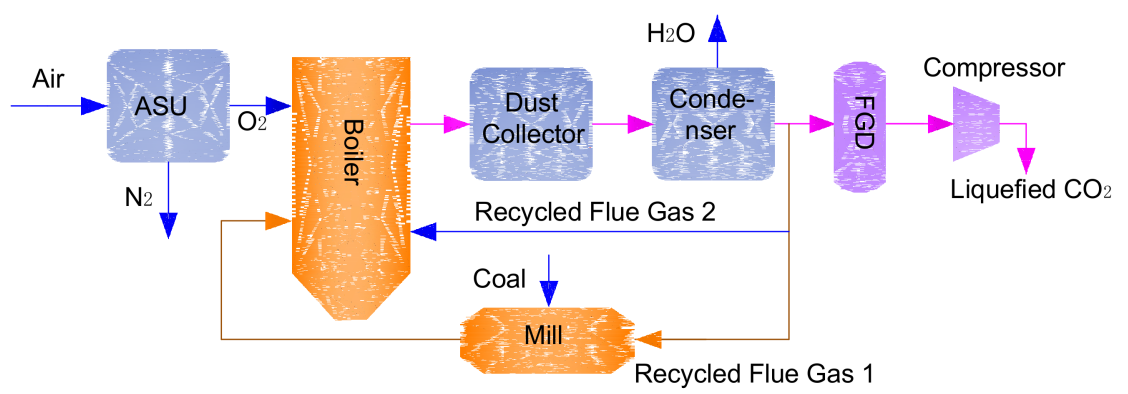

Figure 1. The decarburization system diagram under oxy-fuel combustion.

To maintain the temperature in the furnace within a suitable range, abundant recycled flue gas (usually $70-80 \%$ ) is needed for oxy-fuel combustion. As shown in Figure 1, the recycled flue gas after the water condenser is divided into two parts entering the furnace. This process is called dry flue gas circulation. Recycled flue gas 1 is used to carry coal into the furnace and recycled flue gas 2 is directly introduced into the furnace. The exhaust gas passes through the flue gas desulfurization (FGD) and the compressors, $\mathrm{SO}_{2}$ is removed and the $\mathrm{CO}_{2}$ in the exhaust gas is liquefied. The discussion regarding wet flue gas circulation-where the recycled flue gas is directly introduced into the furnace without a condenser-will be detailed in Section 4.2.

\subsection{Oxy-Enrich Technology}

The system diagram of oxy-enrich combustion is shown in Figure 2. 


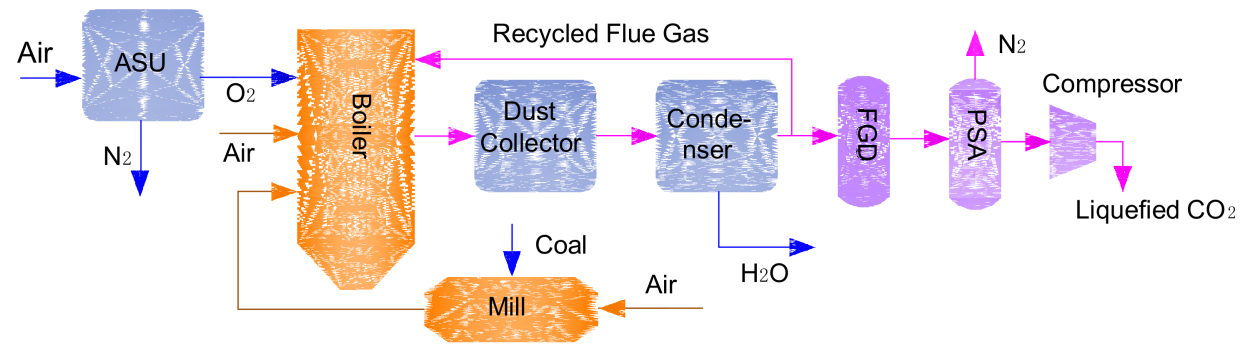

Figure 2. The decarburization system diagram of oxy-enrich combustion.

Under oxy-enrich conditions, the gases introduced into the furnace consist of three parts: air, pure oxygen and recycled flue gas. The air heated by a preheater is divided into two parts: the primary air carries the pulverized coal into the furnace and the remainder of the air is directly introduced into the furnace for burning. Again, the dry flue gas circulation is defined as the recycled flue gas that is introduced into the furnace after the condenser. The exhaust gas after $\mathrm{SO}_{2}$ removal by the FGD goes through a booster fan first and then $\mathrm{CO}_{2}$ is adsorbed in the adsorption tower and the other gases (mainly $\mathrm{N}_{2}$ ) are discharged directly. $\mathrm{CO}_{2}$, desorbed by the vacuum pump, is compressed and liquefied in the compressor. The discussion regarding wet flue gas circulation under oxy-enrich conditions will be presented in detail in Section 4.2.

\subsection{The PSA Cycle}

PSA can be operated on the basis of equilibrium, steric or kinetic selectivity. Using the two-bed cycle for example, Gomes et al. [19] described the PSA cycle in detail. The simple two-bed PSA cycle, involving four steps, is shown in Figure 3.
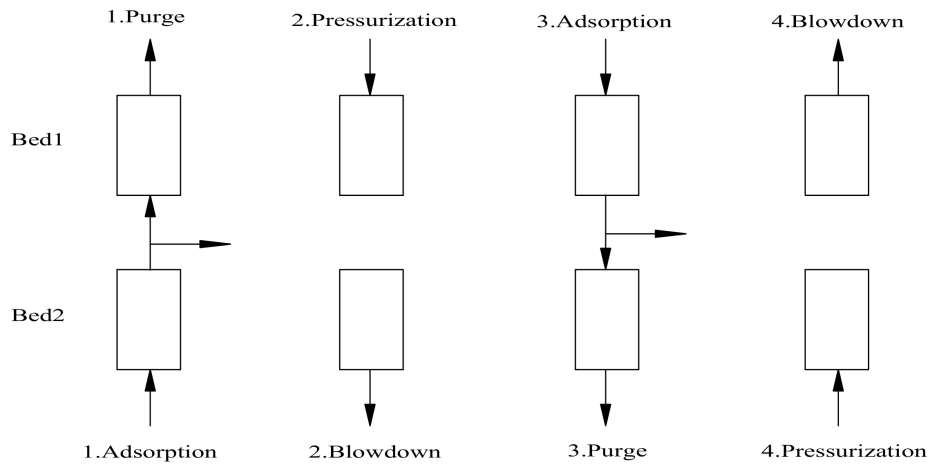

Figure 3. Schematic diagram of a two-bed pressure swing adsorption (PSA) cycle.

During step 1, a high-pressure feed is supplied continuously to bed 2, in which the preferential adsorption of the more strongly adsorbed or faster diffusing species occurs. The less strongly or slower diffusing species are removed as a raffinate product at the bed outlet. A small portion of this stream is expanded to low pressure and is used to purge bed 1 . In step 2, bed 1 is pressurized and the contents of bed 2 are blown down in the reverse flow direction. This completes one half of a cycle. The other half cycle is accomplished similarly in steps 3 and 4.

In $\mathrm{CO}_{2}$ separation from the flue gas, activated carbon, carbon molecular sieves and synthetic zeolites are candidate adsorbents. In general, zeolites have higher adsorption capacities for $\mathrm{CO}_{2}$ and higher equilibrium selectivities for $\mathrm{CO}_{2}$ over $\mathrm{N}_{2}$ than activated carbon [20] but the cost of activated carbon is lower than that of zeolites [21].

The design of a PSA process is very important for $\mathrm{CO}_{2}$ purity and recovery. At present, 4-12 adsorption tower cycle devices have been applied to industrial production. Reynolds et al. [22] evaluated nine stripping PSA cycle configurations, all with a heavy reflux step and the results showed 
that the 5-bed 5-step stripping PSA cycle with a heavy reflux exhibited the highest $\mathrm{CO}_{2}$ purity and recovery in all the PSA cycles evaluated.

During the process of decarburization ammonia synthesis in China, the mixture of adsorbents, activated carbon, $\mathrm{Al}_{2} \mathrm{O}_{3}$, silica gel and diatomaceous earth were reloaded and delaminated in the adsorption tower with different ratios, which reached a very high $\mathrm{CO}_{2}$ purity and recovery.

\section{Calculation Base}

The theoretical combustion temperature in the furnace under dry/wet flue gas circulation of the oxy-fuel and oxy-enrich modes was kept constant, (oxygen purity of $95 \%$ was applied) during the calculations. The selected calculation cases are as follows: $\left(\mathrm{V}_{\mathrm{air}} / \mathrm{V}_{\mathrm{O} 2}\right.$ is the volume ratio of air and oxygen):

Case 0: oxy-fuel combustion $\left(30 \% \mathrm{O}_{2} / 70 \% \mathrm{CO}_{2}\right)$;

Case 1: oxy-enrich combustion, $\mathrm{V}_{\text {air }} / \mathrm{V}_{\mathrm{O} 2}=1$;

Case 2: oxy-enrich combustion, $\mathrm{V}_{\text {air }} / \mathrm{V}_{\mathrm{O} 2}=2$;

Case 3: oxy-enrich combustion, $\mathrm{V}_{\mathrm{air}} / \mathrm{V}_{\mathrm{O} 2}=3$.

The fuel analysis is given in Table 1 .

Table 1. Coal analysis.

\begin{tabular}{cccccccc}
\hline $\mathbf{A}_{\mathrm{ar}} / \%$ & $\mathbf{M}_{\mathrm{ar}} / \%$ & $\mathrm{C}_{\mathrm{ar}} / \%$ & $\mathbf{H}_{\mathrm{ar}} / \%$ & $\mathbf{O}_{\mathrm{ar}} / \%$ & $\mathbf{N}_{\mathrm{ar}} / \%$ & $\mathrm{~S}_{\mathrm{ar}} / \%$ & $\mathrm{LHV} / \mathbf{k J} \cdot \mathbf{k g}^{-1}$ \\
\hline 15.18 & 7.40 & 65.2 & 4.21 & 6.43 & 0.88 & 0.70 & 25,080 \\
\hline \multicolumn{7}{c}{ The subscript of 'ar' indicates the as-received basis. }
\end{tabular}

The main design parameters for the $600 \mathrm{MW}$ furnace are given in Table 2.

Table 2. The main input data for the boiler.

\begin{tabular}{ccc}
\hline Parameter & Unit & Data \\
\hline Superheated steam flow & $\mathrm{t} / \mathrm{h}$ & 2060 \\
Superheated steam pressure & $\mathrm{Mpa} \mathrm{(a)}$ & 17.6 \\
Superheated steam temperature & ${ }^{\circ} \mathrm{C}$ & 541 \\
Reheat steam flow & $\mathrm{t} / \mathrm{h}$ & 1678 \\
Reheat steam inlet and outlet pressures & $\mathrm{Mpa} \mathrm{(a)}$ & $3.97 / 3.79$ \\
Reheat steam inlet and outlet temperatures & ${ }^{\circ} \mathrm{C}$ & $324.7 / 541$ \\
Economizer inlet temperature of water & ${ }^{\circ} \mathrm{C}$ & 282.1 \\
Economizer inlet pressure of water & $\mathrm{Mpa}(\mathrm{a})$ & 19.49 \\
\hline
\end{tabular}

\section{Results and Discussion}

\subsection{Combustion Parameters}

Based on $1 \mathrm{~kg}$ of coal, the volume of gases introduced into the furnace for the four cases are presented in Figure 4.

As shown in Figure 4, for oxy-fuel combustion (Case 0), the gaseous mixture consists of pure oxygen and recycled flue gas and the total volume of the gaseous mixture is the lowest but the volumes of pure oxygen and recycled flue gas were the highest among the four Cases 0-3. For oxy-enrich combustion, the volumes of pure oxygen and recycled flue gas decreased with an increase in the volume ratio of air and oxygen. Under oxy-enrich conditions, coal was burnt in a mixture of air, recycled flue gas and pure oxygen, where air was not only used to support combustion but also to replace part of the recycled flue gas to adjust the temperature in the furnace. Therefore, compared with Case 0 , the volumes of recycled flue gas and pure oxygen are smaller for oxy-enrich combustion. However, the total volume of the gaseous mixture under oxy-enrich conditions increased with an increasing volume ratio of air and oxygen because $\mathrm{N}_{2}$ followed $\mathrm{O}_{2}$ into the furnace. 


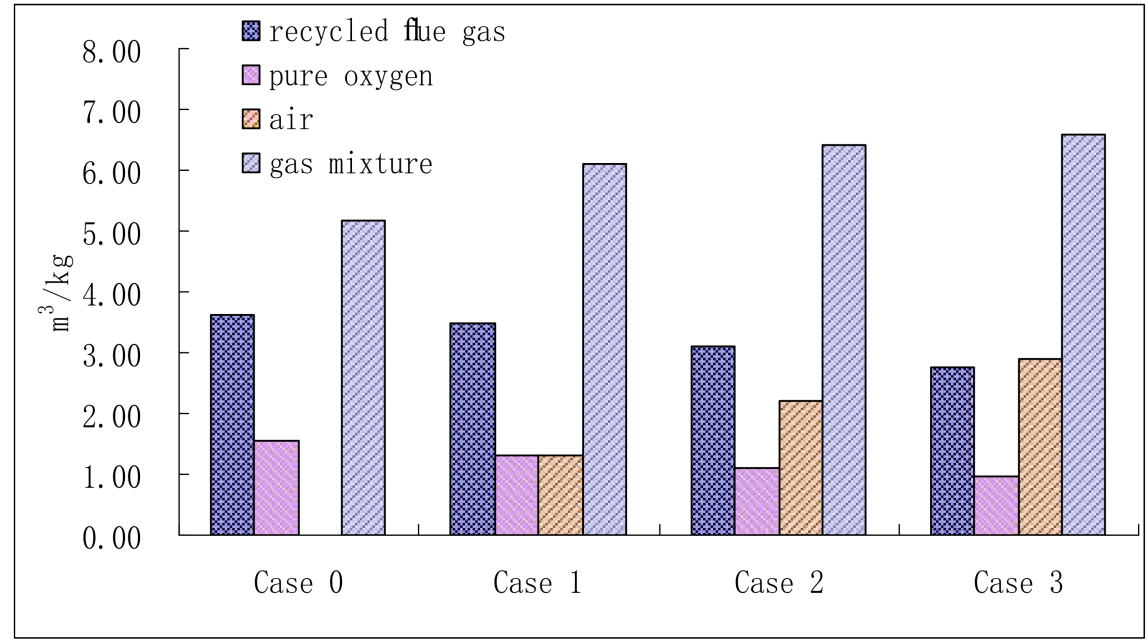

Figure 4. Volume of the gaseous mixtures introduced into the furnace for four cases.

It is well known that the operating costs of the ASU and the flue gas recycling fan are relatively very high for oxy-fuel combustion. As shown in Figure 4, the decreasing volume of pure oxygen and recycled flue gas under oxy-enrich conditions provided the potential for improved economy.

Again based on $1 \mathrm{~kg}$ of coal, the volumes of flue gas in the furnace for four cases are presented in Figure 5.

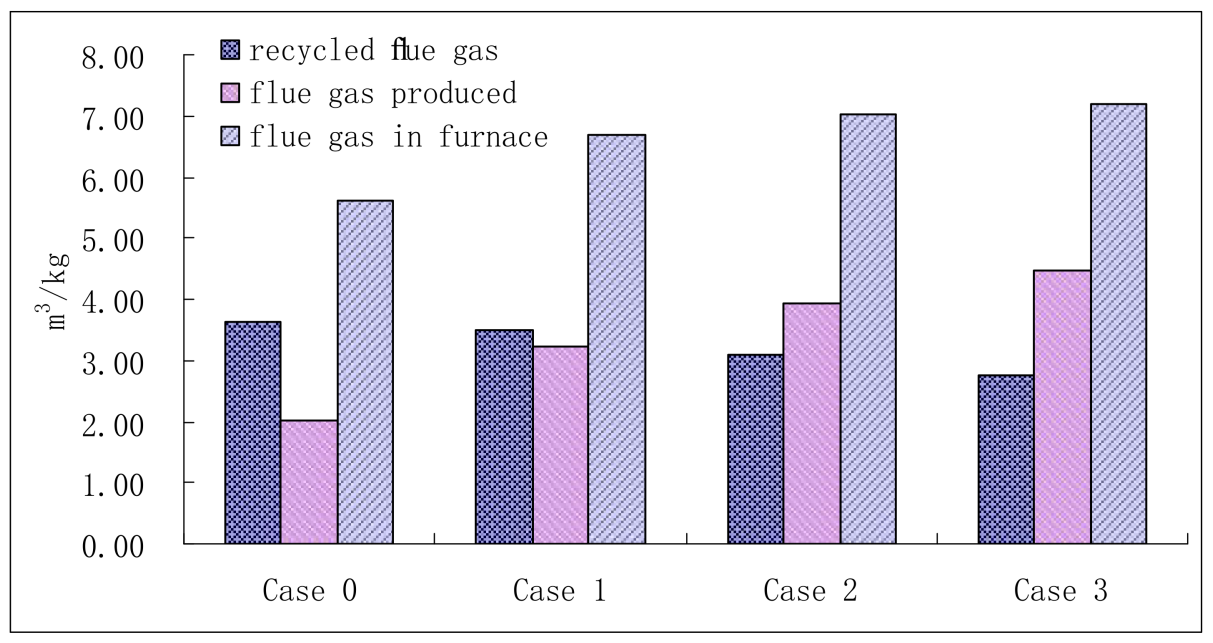

Figure 5. Volume of flue gases in a furnace for four cases.

The flue gases in the furnace consisted of recycled flue gas and the flue gas produced from coal burning. Figure 5 shows that under oxy-fuel combustion (Case 0), the volume of flue gas in the furnace and produced by coal firing were the lowest among the four cases. For oxy-enrich combustion, both gases increased with the volume ratio of air and oxygen. For Case 0 , coal was burnt in a mixture of oxygen and recycled flue gas and the flue gas produced by burning was the lowest because of the absence of $\mathrm{N}_{2}$. For Cases 1-3, when the amount of air increased in the furnace, the volume of gas produced by burning increased and the volume of flue gas in the furnace also changed, which probably led to some changes in the heat transfer characteristics of the furnace, which will be discussed in the future. 


\subsection{Dry and Wet Flue Gas Circulation}

Dry flue gas circulation has been introduced briefly in Section 2.1. Corresponding to dry flue gas circulation, wet flue gas circulation is defined as when the flue gas is introduced into the furnace directly as recycled flue gas, without water vapor removal. The "low-temperature corrosion" on the surfaces of the posterior heater in the boiler are more likely to occur due to the formed $\mathrm{H}_{2} \mathrm{SO}_{4}$ under wet flue gas circulation. For the dry flue gas circulation, because most of the water in the recycled flue gas was removed, the "low-temperature corrosion" decreased greatly but the costs increased because of the added condenser and consumption. The component of flue gas in the furnace is different during dry/wet circulation, which could lead to different radiation characteristics of triatomic gases in the furnace.

The theoretical combustion temperature in the furnace under dry/wet cycle of oxy-fuel and oxy-enrich modes was kept constant (oxygen purity of 95\%) in the following calculations. The components of flue gas in the furnace under dry/wet cycle ways for Case 0-3 are given in Table 3.

Table 3. The components of flue gases under dry/wet flue gas circulation modes.

\begin{tabular}{|c|c|c|c|c|c|c|c|c|}
\hline \multirow{2}{*}{ Case } & \multicolumn{2}{|c|}{ Case 0} & \multicolumn{2}{|c|}{ Case 1} & \multicolumn{2}{|c|}{ Case 2} & \multicolumn{2}{|c|}{ Case 3} \\
\hline & WFGR & DFGR & WFGR & DFGR & WFGR & DFGR & WFGR & DFGR \\
\hline Oxygen concentration in mixture/(\%) & 29.00 & 30.00 & 25.5 & 25.4 & 24.4 & 24.2 & 23.7 & 23.5 \\
\hline Component of flue gas/(\%) & - & - & - & - & - & - & - & - \\
\hline $\mathrm{N}_{2}$ & 3.86 & 5.03 & 39.96 & 44.71 & 50.51 & 54.60 & 56.11 & 59.58 \\
\hline $\mathrm{CO}_{2}$ & 60.60 & 78.91 & 37.74 & 42.24 & 30.93 & 33.44 & 27.31 & 28.99 \\
\hline $\mathrm{H}_{2} \mathrm{O}$ & 31.97 & 11.41 & 18.65 & 8.97 & 15.57 & 8.72 & 13.94 & 8.62 \\
\hline
\end{tabular}

$\mathrm{V}_{\mathrm{REY}} / \mathrm{V}_{\mathrm{LY}}$ : the volume ratio of the recycled flue gas and the flue gas in the furnace; WFGR: wet flue gas recirculation; DFGR: dry flue gas recirculation.

Table 3 shows that the oxygen concentration of the gaseous mixture of oxy-fuel combustion is the highest among Cases $0-3$. The oxygen concentration decreased with an increasing volume ratio of air and oxygen for Cases 1-3, which resulted from more gases introduced into the furnace with the increasing volume ratio of air and oxygen. Similarly, the oxygen concentrations of the gaseous mixture of dry/wet circulation for Cases 0-3 were also different. For Case 0, the $\mathrm{CO}_{2}$ concentration of flue gas for dry circulation was much higher than that for wet circulation. For Cases 1-3, $N_{2}$ that held the largest proportion increased gradually in the gaseous mixture; therefore, the $\mathrm{CO}_{2}$ concentration of flue gas decreased with an increase in the volume ratio of air and oxygen. However, for Cases 1-3, the difference in the $\mathrm{CO}_{2}$ concentration between the dry and wet cycles was not as obvious as it was in Case 0.

On the basis of a consistent theoretical combustion temperature under dry/wet flue gas circulation for Cases 0-3, the volumes of recycled flue gas are shown in Figure 6.

An interesting phenomenon, depicted in in Figure 6, was that the volume of recycled flue gas of the wet flue gas circulations was more than that of the dry flue gas circulations for Case 0 but not for Cases 1-3.

The theoretical combustion temperature was mainly influenced by the components, and volume, of the flue gas. As shown in Table 3, for Case 0 , the $\mathrm{CO}_{2}$ concentration was $60.6 \%$ for wet flue gas recirculation (WFGR) and $78.91 \%$ for dry flue gas recirculation (DFGR). Because the specific heat capacity of $\mathrm{CO}_{2}$ was higher than that of $\mathrm{H}_{2} \mathrm{O}$ and $\mathrm{N}_{2}$, the volume of the recycled flue gas of the wet flue gas circulation could be more than that of the dry flue gas circulation for maintaining a consistent theoretical combustion temperature. For Cases 1-3, there was little difference in $\mathrm{CO}_{2}$ concentration between the dry and wet flue gas circulations (see Table 3), so the key factor was not $\mathrm{CO}_{2}$ but $\mathrm{H}_{2} \mathrm{O}$ and $\mathrm{N}_{2}$, especially $\mathrm{H}_{2} \mathrm{O}$ (because the specific heat capacity of $\mathrm{H}_{2} \mathrm{O}$ was higher than that of $\mathrm{N}_{2}$ ). Thus, the volumes of the recycled flue gas for the wet flue gas circulations were less than those of the dry flue gas circulation. For either dry or wet circulations, the volume of the recycled flue gas of 
Case 0 was the highest among Cases $0-3$. In addition, the recycled flue gas decreased with an increase in the volume ratio of air and oxygen for Cases 1-3.

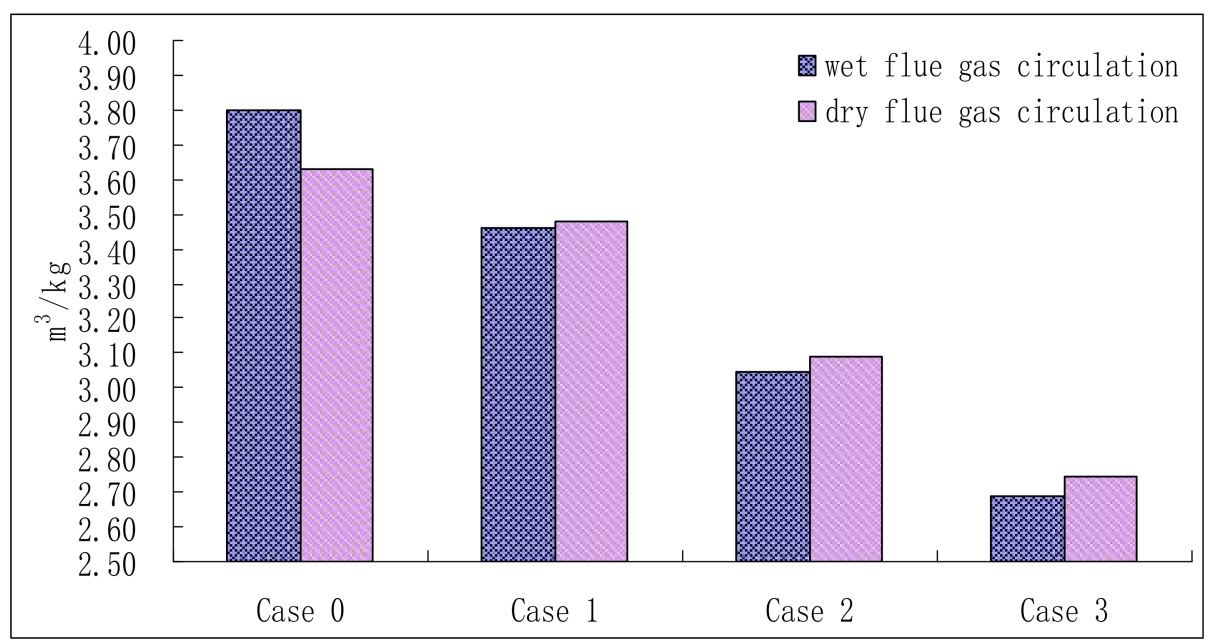

Figure 6. The volume of the recycled flue gas under dry/wet flue gas circulation modes.

\section{Economic Evaluation}

\subsection{Economic Evaluation Model}

\subsubsection{The Total Annual Cost $\left(C_{T}\right)$ of a Power Plant}

To evaluate the $C_{T}$, the following factors should be considered: the annual cost $\left(C_{A I}\right)$, which is also referred to as the amortization cost; the cost of operation and maintenance $\left(\mathrm{OM}, \mathrm{C}_{O M}\right)$ and the annual cost of fuel $\left(C_{F}\right)$.

$$
C_{T}=C_{A I}+C_{O M}+C_{F}
$$

(1) The amortization cost $\left(C_{A I}\right)$

$C_{A I}$ of technical economics used for an economic evaluation is an economic indicator that combines the investment pay-back period, interest rate and the rate of inflation. $C_{A I}$ is defined as follows: [23]

$$
C_{A I}=\varphi f C_{I}=\xi C_{I}
$$

where $\varphi$ is the maintenance factor $\left(\varphi=1.06\right.$ [24]); $\xi$ is the amortization factor; and $C_{I}$ is the total investment cost, which can be described as follows:

$$
\begin{gathered}
C_{I-o x y}=C_{P}+C_{F G D}+C_{S C R}+C_{A S U}+C_{F G}+C_{B U} \\
C_{I-P S A}=C_{P}+C_{F G D}+C_{S C R}+C_{A S U}+C_{P S A}+C_{F G}+C_{B U}
\end{gathered}
$$

where $C_{P}$ is the infrastructure investment for a power plant; $C_{F G D}$ is the desulfurization investment; $C_{S C R}$ is the denitration investment; $C_{A S U}$ is the air separation unit (ASU) investment; $C_{P S A}$ is the PSA investment; $C_{F G}$ is the $\mathrm{CO}_{2}$ compression investment; $C_{B U}$ are the expenses of modifying the boiler; and $f$ expressed as follows is the annual capital recovery factor [25].

$$
\begin{gathered}
f=\left[\frac{q^{(k+P)}-1}{(q-1) q^{(k+P)}}-\frac{q^{P}-1}{(q-1) q^{P}}\right]^{-1} \\
q=(1+i)(1+r)
\end{gathered}
$$


where $P$ is the construction period ( $P=$ one year in this paper), $k$ is the amortization period ( $k=20$ years), $i$ is the interest rate $(i=6.6 \%)$ and $r$ is the rate of inflation $(r=2.424 \%$, the average value of the last ten years in China).

(2) The cost of operation and maintenance $\left(C_{O M}\right)$

$C_{O M}$ is $4 \%$ of the total investment cost $\left(C_{I}\right)$ [26] and can be calculated as follows $\left(r_{O M}=4 \%\right)$ :

$$
C_{O M}=r_{O M} C_{I}
$$

(3) The annual cost of fuel $\left(C_{F}\right)$

$$
C_{F}=c_{F} H M_{F}
$$

where $c_{F}$ is the unit price of standard coal ( $c_{F}=91 \$ / \mathrm{t}$ in this study), $H$ is the number of operation hours $(H=7200)$ and $M_{F}$ is the annual consumption of standard coal.

(4) The revenue from $\mathrm{CO}_{2}$ sale $\left(\mathrm{C}_{\mathrm{CO}_{2}}\right)$

High-purity $\mathrm{CO}_{2}$ obtained from the flue gas can be utilized to produce urea, methanol, drinks, dry ice and can enhance oil/gas/coal-bed-methane recovery $\left(\mathrm{CO}_{2}\right.$-EOR/EGR/ECMR). Thus, $\mathrm{C}_{\mathrm{CO}_{2}}$ can counteract part of the total cost and decrease the unit electricity cost. In China, a market price of $15-25 \$ / t$ of industrially produced $\mathrm{CO}_{2}$ for EOR is acceptable.

The $\mathrm{C}_{\mathrm{CO}_{2}}$ can be described as follows:

$$
\mathrm{C}_{\mathrm{CO}_{2}}=r_{\mathrm{CO}_{2}} c_{\mathrm{CO}_{2}} \mathrm{M}_{\mathrm{P}}
$$

where $r_{\mathrm{CO}_{2}}$ is the $\mathrm{CO}_{2}$ capture rate $\left(r_{\mathrm{CO}_{2}}=90 \%\right.$ [27]), $c_{\mathrm{CO}_{2}}$ is the unit price of the $\mathrm{CO}_{2}$ sale and $\mathrm{M}_{\mathrm{P}}$ is the annual amount of $\mathrm{CO}_{2}$ emissions.

\subsubsection{The Cost of Electricity}

With the decarburization system added, there are two different methods used to calculate the electricity cost.

Without considering the revenue from the $\mathrm{CO}_{2}$ sale, the cost of electricity- $E_{C O E 1}$ with a dimension of $\$ / M W h-$ is calculated by

$$
E_{\mathrm{COE1}}=C_{T} /\left(W_{\text {net }} \times H\right)
$$

Considering the revenue from the $\mathrm{CO}_{2}$ sale, the cost of electricity $-E_{\mathrm{COE} 2}-$ is calculated by

$$
E_{\mathrm{COE} 2}=\left(C_{T}-C_{\mathrm{CO}_{2}}\right) /\left(W_{\text {net }} \times H\right)
$$

where $W_{\text {net }}$ is the net electricity output (MW).

\subsubsection{The $\mathrm{CO}_{2}$ Avoidance Cost (CAC)}

The $\mathrm{CO}_{2}$ avoidance cost (CAC) is an economic indicator widely used in the techno-economic evaluation of $\mathrm{CO}_{2}$ emission control systems. This cost is the cost to avoid $\mathrm{CO}_{2}$ emission (\$/t). The CAC ranges from 26 to $42 \$ / t$ according to References [26,28] and can be calculated as follows [24]:

$$
E_{C A C}=\frac{E_{C O E 2}-E_{C O E-a i r}}{m_{P-a i r}-m_{p}}
$$

where $m_{p}$ is the unit $\mathrm{CO}_{2}$ emission amount $\left(\mathrm{tCO}_{2} / \mathrm{MWh}\right)$ and the subscript "air" identifies a conventional coal-fired plant. $E_{C O E-a i r}$ and $m_{p}$ can be calculated by Equations (10) and (13), respectively.

$$
m_{p}=M_{P} /\left(W_{n e t} \times H\right)
$$




\subsection{Results and Discussion}

The base data applied to the calculations originated from a Chinese power plant: a $600 \mathrm{MW}$ coal-fired boiler with a desulfurization and denitration device; economic parameters of a PSA device according to shift gas decarburization for a 180-thousand-ton Chinese ammonia plant; ASU and $\mathrm{CO}_{2}$ compression [28] and the expense of modifying the boiler can be found in the literature [29]. It was also important to note that $\mathrm{CO}_{2}$ price may change drastically due to massively switching the big electro installations into $\mathrm{CO}_{2}$ capturing and the costs of $\mathrm{CO}_{2}$ emissions and carbon prices are highly uncertain in the future. Therefore, the economic efficiency of oxy-fuel combustion and oxy-enrich combustion were only evaluated based on the current situation.

The capital costs and the energy consumptions of the $\mathrm{CO}_{2}$ compressor, ASU and PSA for four cases are given in Figure 7.

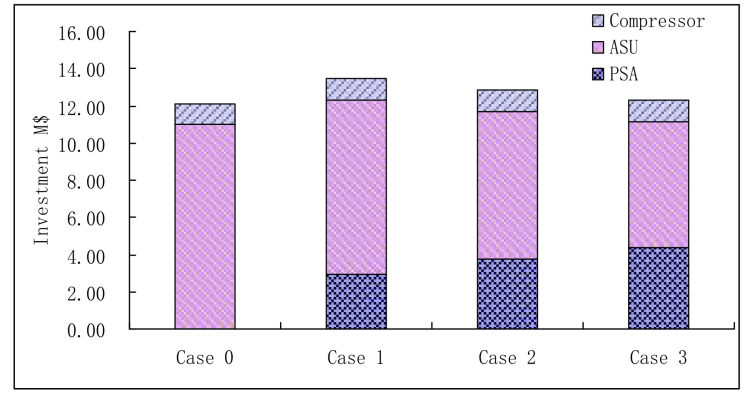

(a)

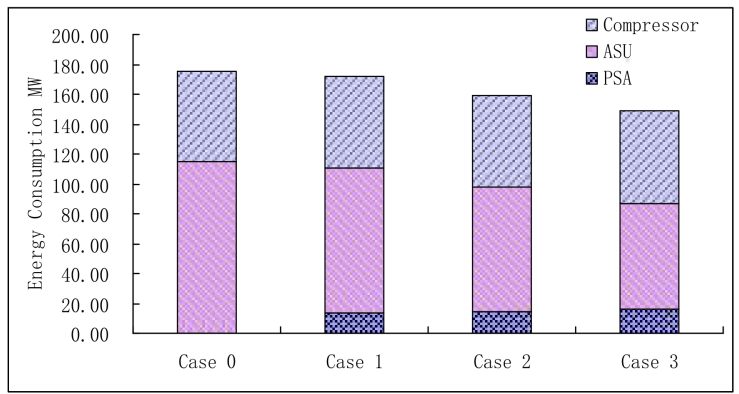

(b)

Figure 7. The investment and energy consumption. (a) The investment; (b) The energy consumption.

The capital cost and the energy consumption of PSA increased with an increase in the volume ratio of air and oxygen for oxy-enrich combustion but not for ASU. For Cases 0-3, the total capital costs of the three devices $\left(\mathrm{CO}_{2}\right.$ compressor, ASU and PSA, $\left.\mathrm{M} \$\right)$ were $\$ 12.12,13.44,12.84$ and $12.30 \mathrm{M}$, respectively, and the total energy consumption (MW) values were 175.14, 171.64, 158.81 and $148.65 \mathrm{MW}$, respectively. Compared with Case 0 , the capital costs of the three devices were more for Cases 1-3 but Case 3 was very close to Case 0 . However, the total energy consumption of Cases 1-3 were always less than that of Case 0. For Cases 1-2, the decrease in the capital costs of ASU relative to Case 0 were smaller than the increase in the capital costs of PSA. However, when the volume ratio of air and oxygen increased to 3 (Case 3), the investments of ASU and PSA approximately counteract each other. In addition, the higher the volume ratio of air and oxygen is, the more flue gas could be purified by the PSA decarburization device per unit time, which leads to increased capital costs and energy consumption of the PSA but the capital cost and energy consumption of the ASU was reduced.

Economic analysis results are provided in Table 4.

Table 4. The economic analysis results of the unit.

\begin{tabular}{cccccc}
\hline Case & Air Combustion & Case 0 & Case 1 & Case 2 & Case 3 \\
\hline Total investment cost $(\mathrm{M} \$)$ & 449.14 & 550.65 & 568.03 & 564.56 & 561.05 \\
\hline Amortization cost $(\mathrm{M} \$ / \mathrm{y})$ & 57.69 & 70.73 & 72.96 & 72.52 & 72.07 \\
\hline Cost of O\&M $(\mathrm{M} \$ / \mathrm{y})$ & 17.97 & 22.03 & 22.72 & 22.58 & 22.44 \\
\hline Annual cost of fuel $(\mathrm{M} \$ / \mathrm{y})$ & 147.05 & 142.21 & 142.82 & 143.52 & 144.23 \\
\hline Revenue from $\mathrm{CO}_{2}$ sale $(\mathrm{M} \$ / \mathrm{y})$ & 0 & 105.44 & 107.63 & 106.41 & 106.93 \\
\hline Net electricity output $(\mathrm{MW})$ & 564.85 & 393.21 & 394.68 & 407.54 & 417.70 \\
\hline Annual $\mathrm{CO}_{2}$ missions $(\mathrm{Mt} / \mathrm{y})$ & 3.8764 & 0.3372 & 0.3444 & 0.3405 & 0.3422 \\
\hline
\end{tabular}


Table 4. Cont.

\begin{tabular}{cccccc}
\hline Case & Air Combustion & Case 0 & Case 1 & Case 2 & Case 3 \\
\hline $\begin{array}{c}\text { Not considering the revenue from } \mathrm{CO}_{2} \\
\text { sale, the cost of electricity }(\$ / \mathrm{MWh})\end{array}$ & 54.77 & 83.00 & 83.92 & 81.33 & 79.39 \\
\hline $\begin{array}{c}\text { Considering the revenue from } \mathrm{CO}_{2} \text { sale } \\
\text { the cost of electricity }(\$ / \mathrm{MWh})\end{array}$ & 54.77 & 45.75 & 46.05 & 45.06 & 43.83 \\
\hline $\mathrm{CO}_{2}$ avoidance cost $(\$ / \mathrm{t})$ & - & 33.85 & 35.06 & 31.73 & 29.33 \\
\hline Coal-consuming rate $(\mathrm{g} /(\mathrm{KWh}))$ & 309.01 & 428.79 & 429.68 & 417.90 & 409.71 \\
\hline
\end{tabular}

As shown in Table 4, if the revenue from the $\mathrm{CO}_{2}$ sale was not considered, the electricity costs of Cases 0-3 were more than that of air combustion without a decarburization system, because the capital costs and energy consumption can increase due to the additional decarburization system of Cases 0-3. Notably, the $\mathrm{CO}_{2}$ avoidance cost of Case 1 was just over that of oxy-fuel combustion. A decrease in the capital cost for the ASU relative to Case 0 was not enough to counteract the increased cost of the PSA decarburization system, which leads to a relatively high cost of $\mathrm{CO}_{2}$ avoidance. However, when the volume ratio of air and oxygen was 2-3 (Cases 2 or 3), the $\mathrm{CO}_{2}$ avoidance cost was lower than that of oxy-fuel combustion.

The service power rates and power efficiencies of five cases are shown in Figure 8.

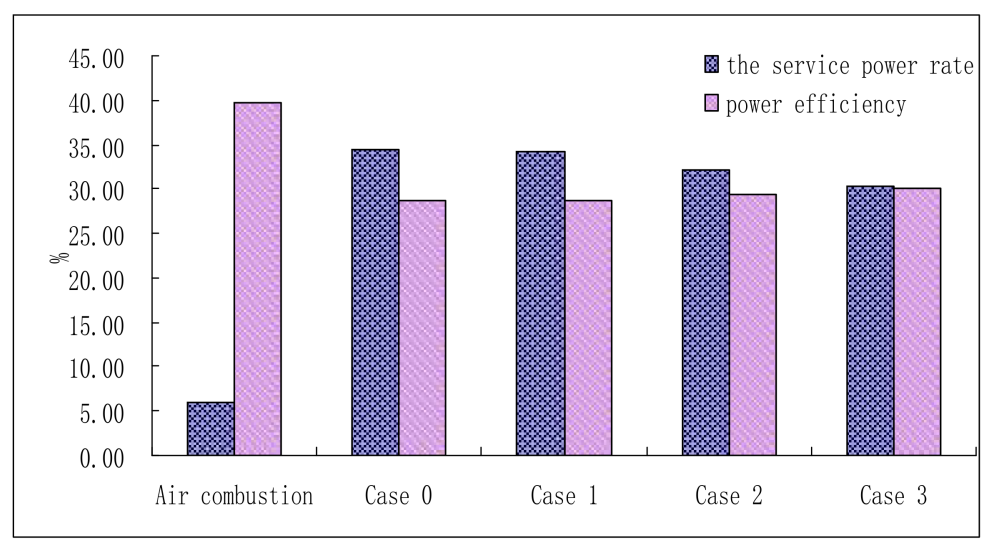

Figure 8. The service power rate and power efficiency for five cases.

Figure 8 shows that the net electricity output of the unit of Cases $0-4$ was less than that of air combustion due to the additional decarburization system. As a result, the power efficiency decreased and the service power rate increased greatly. Additionally, the service power rates and power efficiencies of Case 0 and Case 1 were very close to each other. Compared to Case 0 , the service power rates of Case 2 and Case 3 were lower but they had higher power efficiencies. During oxy-enrich combustion, an increase in the energy consumption of the PSA decarburization device could be compensated for by the decrease in the energy consumption of the ASU and when the volume ratio of air and oxygen grew, the net electricity output of the unit obviously increased with the changes in the service power rate and power efficiency.

\section{Conclusions}

The concept of "oxy-enrich combustion" was discussed in this study. The gases for coal combustion were composed of pure oxygen, air and some recycled flue gases and the $\mathrm{CO}_{2}$ concentration in the flue gas was approximately $30-40 \%$. Thus, $\mathrm{CO}_{2}$ in the flue gas could easily be removed by PSA. Techno-economic analyses of a $600 \mathrm{MW}$ pulverized coal boiler were carried out during oxy-fuel combustion and oxy-enrich combustion. The main conclusions are outlined as follows: 
(1) The demand of oxy-enrich combustion for pure oxygen was less than that of oxy-fuel combustion, which leads to fewer capital and operating costs for the ASU. The air entering the furnace of oxy-enrich combustion played a role in adjusting furnace temperature; therefore, the recycled flue gas was less than that of oxy-fuel combustion, which leads to lower operating costs of the recycle fan.

(2) When the ratio of air and oxygen was 1 during oxy-enrich combustion, the service power rate, the unit power supply and $\mathrm{CO}_{2}$ emissions costs were higher than those during oxy-fuel combustion. However, when the volume ratio was $2-3$, the economy of oxy-enrich combustion with PSA was more advantageous.

(3) The volume of flue gas in the furnace per unit time of oxy-fuel combustion and oxy-enrich combustion were less than that of air combustion and the characteristics of radiation and convective heat transfer could be changed, which could lead to some changes in the boiler structure.

Acknowledgments: This work was supported by the National Key R\&D Program of China (2016YFB0600701), the Hebei Province Natural Science Foundation (E2016502094) and the Fundamental Research Funds for the Central Universities (2017MS120).

Author Contributions: Ming Lei conducted the calculation and wrote the paper; Ming Lei and Cen Sun analyzed the data; Chunbo Wang provided the original idea and gave the main technical guidance.

Conflicts of Interest: The authors declare no conflict of interest.

\section{References}

1. Dmitrienko, M.A.; Strizhak, P.A.; Tsygankova, Y.S. Technoeconomic Analysis of Prospects of Use of Organic Coal-Water Fuels of Various Component Compositions. Chem. Petrol. Eng. 2017, 53, 195-202. [CrossRef]

2. Dmitrienko, M.A.; Strizhak Pavel, A. Coal-water slurries containing petrochemicals to solve problems of air pollution by coal thermal power stations and boiler plants: An introductory review. Sci. Total Environ. 2018, 613-614, 1117-1129. [CrossRef] [PubMed]

3. Dmitrienko, M.A.; Strizhak Pavel, A. Environmentally and economically efficient utilization of coal processing waste. Sci. Total Environ. 2017, 598, 21-27. [CrossRef] [PubMed]

4. Chen, L.; Yong, S.Z.; Ghoniem, A.F. Oxy-fuel combustion of pulverized coal: Characterization, fundamentals, stabilization and CFD modeling. Prog. Energy Combust. Sci. 2012, 38, 156-214. [CrossRef]

5. Xu, G.; Liang, F.F.; Yang, Y.P.; Hu, Y.; Zhang, K.; Liu, W.Y. An improved $\mathrm{CO}_{2}$ separation and purification system based on cryogenic separation and distillation theory. Energies 2014, 7, 3484-3502. [CrossRef]

6. Gou, X.; Wu, C.F.; Zhang, K.; Xu, G.Y.; Si, M.; Wang, Y.T.; Wang, E.Y.; Liu, L.S.; Wu, J.X. Low temperature performance of selective catalytic reduction of $\mathrm{NO}$ with $\mathrm{NH}_{3}$ under a concentrated $\mathrm{CO}_{2}$ atmosphere. Energies 2015, 8, 12331-12341. [CrossRef]

7. Lei, K.; Ye, B.Q.; Cao, J.; Zhang, R.; Liu, D. Combustion characteristics of single particles from bituminous coal and pine sawdust in $\mathrm{O}_{2} / \mathrm{N}_{2}, \mathrm{O}_{2} / \mathrm{CO}_{2}$ and $\mathrm{O}_{2} / \mathrm{H}_{2} \mathrm{O}$ atmospheres. Energies 2017, 10, 1695. [CrossRef]

8. The future of coal. Massachusetts Institute of Technologyl. Available online: http://web.mit.edu/coal/ (accessed on 14 March 2007).

9. Zanganeh, K.E.; Shafeen, A. A novel process integration, optimization and design approach for large-scale implementation of oxy-fired coal power plants with $\mathrm{CO}_{2}$ capture. Int. J. Greenh. Gas Control 2007, 1, 47-54. [CrossRef]

10. Doukelis, A.; Vorrias, I.; Grammelis, P.; Kakaras, E.; Whitehouse, M.; Riley, G. Partial $\mathrm{O}_{2}$-fired coal power plant with post-combustion $\mathrm{CO}_{2}$ capture: A retrofitting option for $\mathrm{CO}_{2}$ capture ready plants. Fuel 2009, 88, 2428-2436. [CrossRef]

11. Huang, Y.; Wang, M.; Stephenson, P.; Rezvani, S.; McIlveen-Wright, D.; Minchener, A.; Hewitt, N.; Dave, A.; Fleche, A. Hybrid coal-fired power plants with $\mathrm{CO}_{2}$ capture: A technical and economic evaluation based on computational simulations. Fuel 2011, 101, 244-253. [CrossRef]

12. Meratla, Z. Combining cryogenic flue gas emission remediation with a $\mathrm{CO}_{2} / \mathrm{O}_{2}$ combustion cycle. Energy Convers. Manag. 1997, 38, S147-S152. [CrossRef] 
13. Wang, C.B.; Lei, M.; Liu, H.M.; Lu, H.Y. Combustion characteristics and nitric oxide release of the pulverized coals under oxy-enrich conditions. Ind. Eng. Chem. Res. 2012, 51, 14355-14360. [CrossRef]

14. Yong, Z.; Mata, V.; Rodrigues, A.E. Adsorption of carbon dioxide at high temperature-a review. Sep. Purif. Technol. 2002, 26, 195-205. [CrossRef]

15. Alpay, E.; Chatsiriwech, D.; Kershenbaum, L.S.; Hull, C.P.; Kirkby, N.F. Combined reaction and separation in pressure swing processes. Chem. Eng. Sci. 1994, 49, 5845-5864. [CrossRef]

16. Chou, C.T.; Wu, C.L.; Chiang, A.S.T. A complementary pressure swing adsorption process configuration for air separation. Sep. Technol. 1994, 4, 93-103. [CrossRef]

17. Feron, P.H.M.; Hendriks, C.A. $\mathrm{CO}_{2}$ Capture Process Principles and Costs. Oli Gas Sci. Technol. 2005, 60, 451-459. [CrossRef]

18. Sekkappan, G.; Melling, P.J.; Anheden, M.; Lindgren, G.; Kluger, F.; Molinero, I.S.; Maggauer, C.; Doukelis, A. Oxy-fuel technology for $\mathrm{CO}_{2}$ capture from advanced supercritical pulverized fuel plants. In Proceedings of the 8th International Conference on Greenhouse Gas Control Technologies, Trondheim, Norway, 19-22 June 2006.

19. Gomes, V.G.; Yee, K.W.K. Pressure swing adsorption for carbon dioxide sequestration from exhaust gases. Sep. Purif. Technol. 2002, 28, 161-171. [CrossRef]

20. Chue, K.T.; Kim, J.N.; Yoo, Y.J.; Cho, S.H.; Yang, R.T. Comparison of activated carbon and zeolite 13X for $\mathrm{CO}_{2}$ recovery from flue gas by pressure swing adsorption. Ind. Eng. Chem. Res. 1995, 34, 591-598. [CrossRef]

21. Plaza, M.G.; Pevida, C.; Arias, B.; Fermoso, J.; Casal, M.D.; Martín, C.F.; Rubiera, F.; Pis, J.J. Development of low-cost biomass-based adsorbents for post-combustion $\mathrm{CO}_{2}$ capture. Fuel 2009, 88, 2442-2447. [CrossRef]

22. Reynolds, S.P.; Mehrotra, A.; Ebner, D.A.; Ritter, J.A. Heavy reflux PSA cycles for $\mathrm{CO}_{2}$ recovery from flue gas: Part I. Performance evaluation. Adsorption 2008, 14, 399-413. [CrossRef]

23. Valero, A.; Lozano, M.A.; Serra, L.; Tsatsaronis, G.; Pisa, J.; Frangopoulos, C.; Spakovsky, M.R. CGAM problem: Definition and conventional solution. Energy 1994, 19, 279-286. [CrossRef]

24. Xiong, J.; Zhao, H.B.; Zheng, C.G.; Liu, Z.H.; Zeng, L.D.; Liu, H.; Qiu, J.R. An economic feasibility study of $\mathrm{O}_{2} / \mathrm{CO}_{2}$ recycle combustion technology based on existing coal-fired power plants in China. Fuel 2009, 88, 1135-1142. [CrossRef]

25. Silveira, J.L.; Tuna, C.E. Thermoeconomic analysis method for optimization of combined heat and power systems. Part I. Prog. Energy Combust. Sci. 2003, 29, 479-485. [CrossRef]

26. Singh, D.; Croiset, E.; Douglas, P.L.; Douglas, M.A. Techno-economic study of $\mathrm{CO}_{2}$ capture from an existing coal-fired power plant: MEA scrubbing vs $\mathrm{O}_{2} / \mathrm{CO}_{2}$ recycle combustion. Energy Convers. Manag. 2003, 44, 3073-3091. [CrossRef]

27. Buhre, B.J.P.; Elliott, L.K.; Sheng, C.D.; Gupta, R.P.; Wall, T.F. Oxy-fuel combustion technology for coal-fired power generation. Prog. Energy Combust. Sci. 2005, 31, 283-307. [CrossRef]

28. Andersson, K.; Johnsson, F. Process evaluation of an $865 \mathrm{MW}$ lignite fired $\mathrm{O}_{2} / \mathrm{CO}_{2}$ power plant. Energy Convers. Manag. 2006, 47, 3487-3498. [CrossRef]

29. Simbeck, D.R. $\mathrm{CO}_{2}$ mitigation economics for existing coal-fired power plants. In Proceedings of the 1st National Conference on Carbon Sequestration, Washington, DC, USA, 14-17 May 2001.

(C) 2018 by the authors. Licensee MDPI, Basel, Switzerland. This article is an open access article distributed under the terms and conditions of the Creative Commons Attribution (CC BY) license (http://creativecommons.org/licenses/by/4.0/). 